\title{
Protection, promotion and support of breast-feeding in Europe: current situation
}

\author{
Adriano Cattaneo', Agneta Yngve ${ }^{2, *}$, Berthold Koletzko ${ }^{3}$ and Luis Ruiz Guzman ${ }^{4}$ \\ on behalf of the 'Promotion of Breastfeeding in Europe' project \\ ${ }^{1}$ Unit for Health Services Research and International Cooperation, Istituto per I'Infanzia, Trieste, Italy: ${ }^{2}$ Unit for \\ Preventive Nutrition, Department of Biosciences at Novum, Karolinska Institute, SE 14657 Huddinge, Sweden: \\ ${ }^{3}$ Metabolic Diseases and Nutrition, Dr von Hauner Children's Hospital, University of Munich, Germany: ${ }^{4}$ Baby \\ Friendly Hospital Initiative, Barcelona, Spain
}

Submitted 24 January 2004: Accepted 30 June 2004

\begin{abstract}
Objective: To describe the current situation regarding protection, promotion and support of breast-feeding in Europe, as a first step towards the development of a blueprint for action.

Design and setting: A questionnaire was completed by 29 key informants and 128 other informants in the EU, including member states, accession and candidate countries.

Results: EU countries do not fully comply with the policies and recommendations of the Global Strategy on Infant and Young Child Feeding that they endorsed during the 55th World Health Assembly in 2002. Some countries do not even comply with the targets of the Innocenti Declaration (1990). Pre-service training on breast-feeding practice is inadequate and in-service training achieves only low to medium coverage. The Baby Friendly Hospital Initiative is well developed only in three countries; in 19 countries, less than $15 \%$ of births occur in baby-friendly hospitals. The International Code of Marketing of Breastmilk Substitutes, endorsed in 1981 by all countries, is not fully applied and submitted to independent monitoring. The legislation for working mothers meets on average the International Labour Organization standards, but covers only women with full formal employment. Voluntary mother-to-mother support groups and trained peer counsellors are present in 27 and 13 countries, respectively. Breast-feeding rates span over a wide range; comparisons are difficult due to use of non-standard methods. The rate of exclusive breast-feeding at 6 months is low everywhere, even in countries with high initiation rates.

Conclusions: EU countries need to revise their policies and practices to meet the principles inscribed in the Global Strategy on Infant and Young Child Feeding in order to better protect, promote and support breast-feeding.
\end{abstract}

Keywords
Breast-feeding
Europe
The need to protect, promote and support breast-feeding is unquestionable. It represents a public health priority everywhere, as confirmed by the Global Strategy on Infant and Young Child Feeding unanimously approved by the 55th World Health Assembly (WHA) in $2002^{1}$. In Europe, the EC-supported expert report EURODIET was initiated in 1998 with the aim of contributing to a co-ordinated EU and Member State programme on nutrition, diet and healthy lifestyles. The final report from the EURODIET project strongly recommended a review of existing activities and the development and implementation of an action plan for the promotion of breast-feeding ${ }^{2-4}$. As a follow-up on EURODIET, France during its Presidency of the Council chose to concentrate on the nutrition situation in Europe.
The so-called French Initiative on nutrition highlighted the need for action on breast-feeding surveillance and promotion $^{5}$. The French Initiative led to the Council Resolution on Nutrition and Health in December 2000, where breast-feeding was officially identified as a priority ${ }^{6}$. The EU-funded project 'Promotion of Breastfeeding in Europe' arose as a consequence of EURODIET, the French initiative and the Council resolution. Its objective is to develop a Blueprint for Action on Breastfeeding that countries can use as a model for planning initiatives at national and local level. The present article on the current situation in 29 countries is based on the first official project document. It was followed by a review of interventions and by the blueprint for action. 


\section{Methods}

Data were gathered through a questionnaire completed during January and February 2003. The questionnaire was originally sent to key people in the $15 \mathrm{EU}$ member states, Iceland, Norway and Switzerland. Through the European Office of the World Health Organization (WHO), the questionnaire was also sent to 10 accession (Estonia, Latvia, Lithuania, Poland, Hungary, Czech Republic, Slovak Republic, Malta, Slovenia, Cyprus) and two candidate countries (Bulgaria, Romania). Cyprus was the only country contacted that did not respond and Turkey was the only candidate country not contacted by WHO for this project. The UK completed four separate questionnaires for England, Wales, Scotland and Northern Ireland. The key informants represented different sectors within the participant countries: eight informants were employed by governmental bodies, 11 by other public institutions (universities, hospitals, institutes of public health) and 10 by non-government organisations (NGOs), including national committees for the United Nations Children's Fund (UNICEF). Key informants gathered data from a total of 128 other informants from governments, public institutions and NGOs. In 10 countries, key informants were national breast-feeding co-ordinators or members of national breast-feeding committees.

The questionnaire was split into the sections used to report the results. There was room for additional comments at the end of each section; some of the reported results derive from these comments and may not reflect the situation in all countries. The quality of the data is not uniform, reflecting the different development of health information systems in Europe. When data are missing it means that key and other informants, the best possible sources of data in each country, were unable to find the information. The compiled results are the outcome of revisions/suggestions supplied by key informants on drafts circulated via email.

\section{Results}

\section{Policy, planning and management}

Table 1 shows the number of countries with a national and/or local policy (i.e. a series of simple statements on what is recommended) and/or a national recommendation (i.e. a more detailed and referenced document) for each of the criteria stated in the first column. Only five countries (Latvia, Lithuania, Malta, Poland and the Slovak Republic) have policies that meet all four criteria. Policies in Bulgaria, Denmark, Germany, Estonia, Spain, Greece, The Netherlands, Norway and Sweden meet three out of four criteria. France, Luxembourg, Ireland, Sweden and the UK issued policy statements recommending 'exclusive breastfeeding for 6 months' subsequent to the collection of data. All the other countries have no national policies at all or have policies that do not meet the stated criteria.
Table 1 Countries with policies and recommendations meeting stated criteria $(n=29)$

\begin{tabular}{lccc}
\hline Criterion & $\begin{array}{c}\text { National } \\
\text { policy }\end{array}$ & $\begin{array}{c}\text { Local } \\
\text { policy }\end{array}$ & $\begin{array}{c}\text { National } \\
\text { recommendation }\end{array}$ \\
\hline $\begin{array}{c}\text { Help mothers to start breast- } \\
\text { feeding soon after birth }\end{array}$ & 14 & 15 & 23 \\
$\begin{array}{c}\text { Breast-feed exclusively } \\
\text { for } 6 \text { months }\end{array}$ & 17 & 11 & 20 \\
$\begin{array}{c}\text { Continue breast-feeding up } \\
\text { to 2 years and beyond }\end{array}$ & 4 & 7 & 10 \\
$\begin{array}{l}\text { Implement the Ten Steps for } \\
\text { Successful Breastfeeding }\end{array}$ & 14 & 14 & 23 \\
\hline
\end{tabular}

The Czech Republic is currently revising its 1992 and 1995 policies. All countries, except Malta and The Netherlands, have national recommendations that meet at least one of the four criteria. In the majority of cases these recommendations were developed by professional associations; in other cases by national breast-feeding committees. Policies and recommendations, where they exist, are usually (19 countries) well disseminated through journals, newsletters and booklets, mostly to health professionals, less often to the public. However, there is almost no public monitoring of adherence to, or implementation of, policies and recommendations, except in Iceland, Poland, Slovak Republic, Slovenia, Sweden and Scotland.

National plans including general objectives and recommended strategies have been developed in 15 countries; in some of the others a plan is being developed or drafted. Where the health system is decentralised, local plans are available. Action plans including specific objectives, targets and activities have been developed in Estonia, Hungary, Ireland, Latvia, Lithuania, The Netherlands, Norway and the UK; not all plans, however, are fully implemented. Greece, Luxembourg, Malta, Austria, Poland, Slovak Republic, Finland and Sweden do not have national and/or local plans and do not envisage developing them.

Sixteen countries have a national co-ordinator, 21 a national committee; Switzerland, Spain, Finland, France, Iceland, Italy and Sweden (now both installed in Sweden) lack both, 13 years after the Innocenti Declaration ${ }^{7}$. The amount and type of funding available to national committees and co-ordinators vary greatly. National committees, where they exist, generally have an advisory role. Membership usually includes representatives from relevant health professional groups, academic research organisations, NGOs and mother-to-mother support groups. Some of the national committees do not meet regularly, or do so infrequently. With changes in governments following elections, or when re-shuffles of government portfolios occur, national committees have been suspended or disbanded. National co-ordinators and committees are mostly involved in advocacy, policy, planning and development of guidelines and other written materials; some committees are responsible for training 
and/or the development of training materials, including curricula for pre-service training.

\section{Training}

Several countries have national boards that set standards and certify pre-service education. Only Austria, Bulgaria, Romania, Slovak Republic and the UK, however, have some form of certification of courses on breast-feeding and/or set curricula for breast-feeding education of midwives and nutritionists. In the other countries with such boards, certification and standard setting apply to the generality of pre-service education, and not specifically to breast-feeding. In most countries, there are few skilled breast-feeding trainers at either undergraduate or postgraduate level.

Regarding in-service training, the 18-hour UNICEF/ WHO course on the Baby Friendly Hospital Initiative $(\mathrm{BFHI})^{8}$ has been introduced in 17 countries, mostly with low to medium coverage. The 40-hour WHO/UNICEF course on breast-feeding counselling ${ }^{9}$ has been introduced in 12 countries, also with low to medium coverage. Twenty-five countries have introduced locally adapted/ developed courses with duration ranging from a few hours to a few days. Some of these courses are officially endorsed and lead to a recognised certificate or credits. However, there is little assessment of the quality and effectiveness of training. In-service training coverage is generally higher for nurses and midwives than for doctors; among the latter, paediatricians are more likely to undergo breast-feeding training than obstetricians.

The examination leading to the certificate of International Board Certified Lactation Consultant (IBCLC) is available in 10 countries. In total, 1647 IBCLCs were certified up to the end of 2002; $86 \%$ of them in only six countries: Austria, Switzerland, Germany, Ireland, The Netherlands and the UK.

\section{Baby Friendly Hospital Initiative}

There are national BFHI co-ordinators in 20 countries, some appointed by governments, some by UNICEF and NGOs. National committees for UNICEF in Greece, France and Ireland have virtually no involvement in the BFHI. The implementation of the BFHI has been difficult and slow in many countries. Table 2 shows the number of baby-friendly hospitals (BFHs) and the percentage of births they cover by country; it also indicates if there is at least one teaching hospital among accredited BFHs. The data from The Netherlands includes home care organisations, providing maternity care in the mother's own home, that are assessed using BFHI criteria. Three countries, Sweden, Slovenia and Norway, report very high percentages of births in BFHs; seven countries Switzerland, Czech Republic, Denmark, Luxembourg, Slovak Republic, The Netherlands and the UK - fall within an intermediate range (i.e. 15-50\%), while 19 countries report lower percentages (i.e. $0-15 \%$ ). Ceasing
Table 2 Baby-friendly hospitals (BFHs) by country and coverage of births (2003)

\begin{tabular}{|c|c|c|c|}
\hline Country & $\begin{array}{l}\text { BFHs/total } \\
\text { hospitals }\end{array}$ & $\begin{array}{l}\% \text { of births } \\
\text { in BFHs }\end{array}$ & $\begin{array}{c}\text { Teaching } \\
\text { BFHs }\end{array}$ \\
\hline Austria & $14 / 110$ & 12 & $\nu$ \\
\hline Belgium & $0 / 107$ & 0 & \\
\hline Bulgaria & $5 / 127$ & 8 & $\nu$ \\
\hline Switzerland & $46 / 150$ & 40 & $\nu$ \\
\hline Czech Republic & $30 / 116$ & 23 & $\nu$ \\
\hline Germany & $18 / 1100$ & 3 & $\nu$ \\
\hline Denmark & $11 / 35$ & 22 & $\nu$ \\
\hline Estonia & $1 / 17$ & 2 & \\
\hline Spain & $8 / 498$ & 1.5 & $\nu$ \\
\hline Finland & $4 / 35$ & 7 & \\
\hline France & $2 / 800$ & 0.3 & \\
\hline United Kingdom & $44 / 305$ & $15^{\star}$ & $\nu$ \\
\hline Greece & 0 & 0 & \\
\hline Hungary & $9 / 100$ & 11 & $\nu$ \\
\hline Ireland & $0 / 22$ & 0 & \\
\hline Iceland & $0 / 15$ & 0 & \\
\hline Italy & $7 / 700$ & 1 & \\
\hline Lithuania & $3 / 54$ & 12 & \\
\hline Luxembourg & $2 / 6$ & 35 & $\nu$ \\
\hline Latvia & $4 / 30$ & 8 & \\
\hline Malta & $0 / 3$ & 0 & \\
\hline Netherlands & $24 / 200$ & 25 & $\nu$ \\
\hline Norway & $36 / 57$ & 75 & $\nu$ \\
\hline Poland & $50 / 434$ & 12 & $\nu$ \\
\hline Portugal & $0 / 60$ & 0 & \\
\hline Romania & $10 / 237$ & 5 & $\nu$ \\
\hline Sweden & $52 / 52$ & 100 & $\nu$ \\
\hline Slovenia & $10 / 14$ & 85 & $\nu$ \\
\hline Slovak Republic & $11 / 72$ & 30 & レ \\
\hline
\end{tabular}

* England 8\%; Wales 34\%; Scotland 38\%; Northern Ireland 20\%.

of acceptance of free formula donations is a challenge to the expansion of the BFHI in some countries, as is general under-funding of the initiative with overall cost charged to participating hospitals, and a less than desirable strength of collaboration between the BFHI and health professionals in some places.

\section{International Code and subsequent relevant WHA resolutions}

All 29 countries voted in favour of the International Code of Marketing of Breastmilk Substitutes ${ }^{10}$ and of subsequent relevant WHA resolutions (referred to hereafter as the Code). In 1991, the EU adopted many provisions of the Code in its Directive for the internal market of infant and follow-on formulae ${ }^{11}$. The following year an export Directive and Council Resolution were adopted ${ }^{12,13}$. These Directives, however, have not been revised to take into consideration relevant WHA resolutions approved after 1991. In addition, a number of products covered by the Code are not included in the scope of the Directives and hence in national legislation. The Directives are binding acts; in most EU countries they have regulated the marketing of infant formulae. In accession and candidate countries, this marketing is not yet fully regulated and serious infringements to the Code are reportedly more common ${ }^{13,14}$. 
The enforcement and monitoring of compliance with national laws is the responsibility of different government sectors in different countries. Governments, however, have not, in the main, taken responsibility for enforcement and monitoring of the Code. In countries where compliance with the Code is monitored, this is mainly undertaken by NGOs and consumer associations; where monitoring has been conducted, violations have been reported $^{14}$. Infringements of the Code are normally reported to governments, but even proven infringements are rarely prosecuted or punished. There is a general lack of awareness of the Code among the general public, and health professionals are rarely aware of their responsibilities under the Code. Limited official dissemination of information about the Code and its implementation has taken place in Norway, Finland and Sweden; more information has been circulated in many countries, including accession and candidate countries, by NGOs. Manufacturers of breast milk substitutes have direct contact with mothers through mail, the Internet, telephone help lines, commercial discharge packs and baby clubs. Many of these activities, when promoting products covered by the Code, should be considered as violations. Companies interact regularly also with health professionals and their associations through sponsorship of events, courses, conferences, research and publications; some of these activities may lead to a conflict of interest.

\section{Legislation for working motbers}

Convention 183 on Maternity Protection of the International Labour Organization (ILO) set standards for protecting and supporting breast-feeding among working mothers, including:

- The provision of a minimum of 14 weeks of paid maternity leave (i.e. shorter than the recommended 6 months of exclusive breast-feeding);

- Entitlement to one or more paid breast-feeding/lactation breaks daily or daily reduction of hours of work to promote the longer duration of breast-feeding, without loss of pay;

- Job protection and the non-discrimination of breastfeeding workers ${ }^{15}$.

The ILO recommendations also state that maternity leave payments should be at least two-thirds of previous earnings. The legislative provisions facilitating breastfeeding in the workplace go beyond the ILO recommendations in many countries and are partially implemented in others. Fathers can often share part of the maternity protection benefits granted to mothers under national legislation. Only four governments (Bulgaria, Italy, Romania, Slovak Republic), however, have ratified ILO Convention 183 so far. The standard regarding paid breastfeeding breaks during working time is not frequently met. The UK was the EU country with least compliance with ILO standards, but it has recently extended its paid maternity leave to 6 months. Virtually none of the ILO standards are met in Switzerland, although legal provisions in some cantons do meet the standards. There are groups of women workers not covered by protective legislation in all countries, e.g. women employed for less than 6-12 months at the time of application for maternity leave, those who are self-employed, contract or irregular workers, and working students. In some countries there are differences between women employed in the private and the public sector, especially with regard to the duration of full and/or partial salary during maternity leave and the provision of paid breast-feeding breaks.

\section{Community outreach, including voluntary mother- to-motber support}

Voluntary mother-to-mother support groups are present in 27 countries. Some of these groups were involved in the promotion and support of breast-feeding long before any concerted public health initiatives/activities started. The geographical coverage of these groups is reported as low to medium in all countries, except in France and Scotland where it is rated as high, and in The Netherlands where mother-to-mother support groups have national coverage. In 16 countries these groups have good links with the health-care services and their members have some training in breast-feeding management and support. In 13 countries, peer counsellors - defined as lay (non-health professional) women adequately trained to provide individual support to mothers - and mother-to-mother support groups are funded/grant-aided and/or otherwise supported by providers of regional or national health-care services. Women are made aware of the contact details and services provided by these groups through newsletters, information sheets, telephone directories, the Internet and contacts with health-service providers (during antenatal care or at discharge after delivery). Mothers who need information and/or support usually attend group meetings, or get in touch by phone and increasingly by email and through the Internet. Information and support is usually provided via these channels, but may also be provided through home visits, written materials and videos.

\section{Information, education, communication}

In 16 countries, governments allocate funds for the production of booklets, leaflets, flyers, posters, stickers, videos, TV spots and for workshops; local funds and initiatives are also common. These materials are reviewed and revised as necessary; they are widely and regularly disseminated in some countries, irregularly in others. No provisions are made to audit their results, in terms of coverage and effectiveness, except in Iceland (where it has been shown that mothers usually comply with the written advice), Malta, Norway, Romania and the UK. World Breastfeeding Week activities are implemented in all countries except Iceland, Portugal and Romania. Activities 
are mostly organised by NGOs, with some UNICEF involvement (Bulgaria, Czech Republic, Germany, Estonia, Greece, Latvia, Lithuania, Slovenia, Spain) and government support (Denmark, Hungary, Ireland, Malta, UK). The number of websites devoted to breastfeeding is increasing, developed by government departments, individuals, interest groups, NGOs and BFHI committees.

\section{Monitoring}

Monitoring of breast-feeding rates is generally funded by governments, within the budgets assigned to health-care systems. Monitoring is population-based in Belgium, Greece, France, Ireland, Iceland, Sweden, Scotland, Wales, and in all accession and candidate countries except Romania. Population-based means that data are gathered routinely by health-care providers during contacts with users (delivery, discharge from hospital, metabolic screening, immunisation, well-baby clinics). This routine collection of data achieves differing degrees of completeness. Monitoring is sample-based in Denmark, Spain, Italy, Luxembourg, The Netherlands, Norway, Austria, Portugal, Romania, Finland and the UK (Scotland and Wales also collect population-based data, as stated above), at different and often irregular intervals. Local surveys are conducted in many countries and are often not widely reported. No routine collection/monitoring of breast-feeding data takes place in Switzerland and Germany. Analysis/publication of data usually (but not always) involves a 6-month to 3-year time lag. Dissemination of results is low, as is feedback to health professionals and decision-makers, except in Iceland, The Netherlands, Finland, Sweden, the UK, and in most accession and candidate countries (except Poland and Slovenia). Dissemination to the general public is even poorer. Table 3 shows the available information on breastfeeding rates. The key informants were asked to report data using, as far as possible, the WHO/UNICEF definitions of exclusive, full (exclusive plus predominant) and any breast-feeding ${ }^{16,17}$. The respondents' sources were from published reports in only a small number of cases; in most cases the sources belonged to the so-called 'grey literature', available only within health institutions. Due to varying degrees of incompleteness and inaccuracy, i.e. use of nonstandard methods of data collection and breast-feeding definitions, great care is needed when making comparisons.

\section{Disadvantaged groups}

In 18 countries, there is no specific policy or plan addressing the poor up-take of breast-feeding by mothers from disadvantaged groups. Some specific policy and action plans have been developed and implemented in Czech Republic, Germany, Denmark, Greece, Hungary, Norway, Portugal, Romania, Slovak Republic, Sweden (proposed) and the UK. These address smokers, teenagers, less educated families, lower socio-economic groups, immigrant women or ethnic minority groups, and generally focus on reducing inequalities in health and do not specifically address low breast-feeding rates. Some local projects/activities involve NGOs. In some countries, free formula is given to low-income mothers as an in-kind financial support to child rearing. Where there is monitoring of breast-feeding rates, data are sometimes available by age, education, residence and occupation, but less often by family income, employment status and ethnicity.

\section{Discussion}

Breast-feeding rates in the 29 countries span over a wide range. This may be partly due to varying degrees of accuracy, consistency and completeness in data collection. The WHO breast-feeding definitions are also not widely applied $^{3}$. Inconsistencies are common, even within countries $^{18}$. The establishment of a common EU monitoring system is urgently required. Different social and cultural determinants, as well as flawed policies and unequal support among and within health-care systems, could also explain differences in breast-feeding rates ${ }^{19}$. But it is definitely difficult to understand why initiation and duration of breast-feeding vary so much, and more comparative research is needed. Meanwhile, the only possible conclusion is that breast-feeding rates fall short of the recommended targets set by many national policies, international agencies ${ }^{1}$ and professional associations ${ }^{20-23}$ everywhere, even in countries with a high initiation rate.

A possible explanation is that policies on infants and young child feeding are just beginning to accept universally recognised best practice criteria for breastfeeding protection, promotion and support. Some professional associations have also started to develop or update their recommendations using these criteria. What is missing is a commonly agreed EU document that can function as a template for individual countries. Many countries have yet to achieve the goals and objectives set for 1995 by the Innocenti Declaration ${ }^{7}$. Some countries have advanced more than others and have a national co-ordinator and committee in place, but these are often under-funded and cannot implement much-needed changes. The BFHI, or a similar initiative that promotes changes in hospital practices, is generally implemented but only a limited number of countries have achieved good coverage, despite evidence of effectiveness ${ }^{24}$. Moreover, the BFHI is not usually integrated within national policies and is often regarded as a stand-alone scheme. None of the countries has fully revised its policies in view of the Global Strategy on Infant and Young Child Feeding; yet all European countries, and in fact all WHO Member States, endorsed it at the 55th WHA in 2002 and made a commitment to implement it $^{1}$.

Adequate competency-based training is needed for optimal breast-feeding promotion and support. 


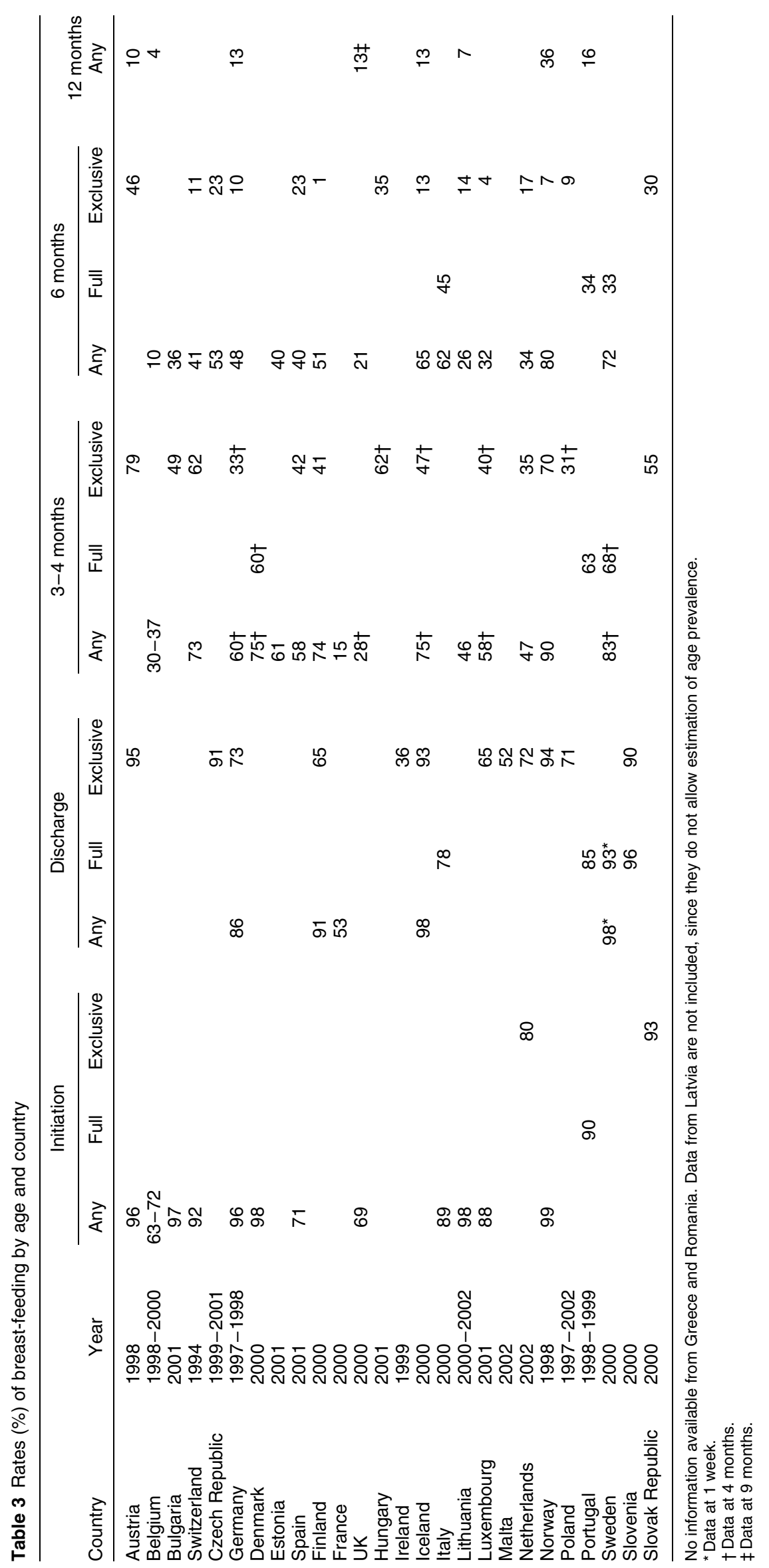


Undergraduate and postgraduate curricula for all healthcare professionals should be revised. This process, while urgently needed, will take a long time to have a positive impact on the competencies of newly qualified health and allied professionals. In the mean time, quality-assessed courses involving clinical competency testing should be used for in-service training ${ }^{25}$. The coverage of such training is currently low. IBCLCs are found in many countries, which may indicate increased awareness of the need for specialist consultants. Mother-to-mother support groups and peer counsellors are present in most countries but their coverage is low to medium. It should be high, given their proven effectiveness in the promotion and support of breast-feeding, especially among disadvantaged groups ${ }^{26-28}$.

The legislation that regulates the marketing of breast milk substitutes falls short of the provisions in the Code in all of the 29 countries. Most EU countries apply the EU Directive of $1991^{11}$, which covers only some provisions of the Code and has not been updated since. The Code itself is not sufficiently known by health professionals and the general public, nor is it adequately monitored ${ }^{29}$. Accession and candidate countries must adopt the EU Directive to achieve full EU membership. EU member states, however, are bound to adopt the EU Directives as a minimum standard, but they are free to provide additional legislative protective measures to safeguard infant and young child health. The EU Directive only applies to infant and followon formulae; it does not apply to preterm and other special formulae or to feeding bottles and teats. It permits certain forms of marketing that are prohibited under the Code, namely promotion to the general public of follow-on formulae, advertising in specialist baby-care magazines and scientific publications, and the donation or low-price sale of supplies for infants fed on infant formula. An updated EU legislation is required, along with a statutory framework for independent monitoring and enforcement.

In many countries, the legislation on maternity protection with relevance to breast-feeding goes beyond the ILO standards ${ }^{15}$; in some countries, however, it does not meet them, especially with regard to breast-feeding/lactation break provisions. Because legislation intended to protect working mothers can only cover employed women and does not cover women who are self-employed, women with short-term or irregular work and working students, special measures are needed to ensure that these mothers receive appropriate care and funds to enable breastfeeding, even in countries where the legislation meets the ILO standards. It is clear that labour market policies are important and need to be improved, if high rates of breastfeeding among working women are to be achieved ${ }^{30}$.

\section{Acknowledgements}

Collection of the information used to write this paper was carried out within the project 'Promotion of Breastfeeding in Europe', financed by the European Commission, Health and Consumer Protection Directorate-General, Directorate G - Public Health (EU Project Contract No. SPC 2002359), and co-ordinated by Adriano Cattaneo. Information from EU accession and candidate countries was gathered through the European Regional Office of WHO in Copenhagen, Denmark, and was analysed by Joceline Pomerleau at the London School of Hygiene and Tropical Medicine.

Members of the 'Promotion of Breastfeeding in Europe' project who provided information: Bichler I (Austria), Moyersoen F (Belgium), Petrova S (Bulgaria), Schneidrová D (Czech Republic), Vinther Jerris T (Denmark), Deikina J (Estonia), Hasunen $\mathrm{K}$ (Finland), Ollivier-Diers $\mathrm{F}$ and Roques N (France), Koletzko B and Przyrembel H (Germany), Benetou V and Zachou T (Greece), Sarlai K (Hungary), Gunnlaugsson G (Iceland), Becker $G$ and Fallon M (Ireland), Cattaneo A, Di Mario S, Macaluso A and Ronfani L (Italy), Braznevica V, Kondrate I and Pudule I (Latvia), Bartkeviciute R (Lithuania), Lehners-Arendt $M$ (Luxembourg), Ellul M (Malta), de Reede A (The Netherlands), Bergljot Bærug A (Norway), Mikiel-Kostyra K (Poland), Loureiro I (Portugal), Parvan C (Romania), Hal'amová V (Slovak Republic), Gabrijelcic-Blenkus M (Slovenia), Ruiz Guzman L (Spain), Holmström U, Kylberg E, Sjöström M and Yngve A (Sweden), Bucher C (Switzerland), Calvert J, Carson C, Reddy S, Sky S and Warren J (UK), Radford A (UK Baby Friendly Hospital Initiative), Lhotska L (International Baby-Food Action Network), Fleischer Michaelsen K (International Society for Research on Human Milk and Lactation), Pomerleau J (ECHOHOST, London School of Hygiene and Tropical Medicine, UK), Robertson A (WHO European Regional Office).

Contributors: A.C. and A.Y. wrote the first draft of the paper, based on the project report submitted to the European Commission. B.K. and L.R.G., as members of the project steering committee, revised the draft and contributed to the final text. All the other project participants and key informants read, commented and approved the manuscript.

\section{References}

1 Global Strategy on Infant and Young Child Feeding. 55th World Health Assembly. Geneva: World Health Organization, 2002.

2 Nutrition \& diet for healthy lifestyles in Europe: science \& policy implications. Public Health Nutrition 2001; 4(2A): 265-73.

3 Yngve A, Sjöström M. Breastfeeding in countries of the European Union and EFTA: current and proposed recommendations, rationale, prevalence, duration and trends. Public Health Nutrition 2001; 4(2B): 631-45.

4 Yngve A, Sjöström M. Breastfeeding determinants and a suggested framework for action in Europe. Public Health Nutrition 2001; 4(2B): 729-39.

5 Health and Human Nutrition: Elements for European Action. Brussels: European Commission, 2000. 
6 Resolution on Health and Nutrition. Brussels: EU Council, 2000.

7 Innocenti Declaration. Florence: United Nations Children's Fund/World Health Oraganization, 1990.

8 Breastfeeding, management and promotion in a babyfriendly hospital: an 18-hour course for maternity staff New York: United Nations Children's Fund/World Health Organization, 1993.

9 Breastfeeding counselling: a training course. Geneva: World Health Organization/United Nations Children's Fund, 1993.

10 International Code of Marketing of Breastmilk Substitutes. Geneva: World Health Organization, 1981.

11 Directive 91/321/EEC. Brussels: European Commission, 1991.

12 European Commission Directive 92/52/EEC. Brussels: European Economic Community, 1992.

13 European Council Resolution 92/C 172/01. Brussels: European Economic Community, 1992.

14 International Baby-Food Action Network (IBFAN). Breaking the Rules, Stretching the Rules 2001. Penang: IBFAN, 2002.

15 Maternity Protection Convention C183. Geneva: International Labour Organization, 2000.

16 Indicators for Assessing Breast-feeding Practices. Geneva: World Health Organization, 1991.

17 Indicators for Assessing Health Facility Practices that Affect Breastfeeding Practices. Geneva: World Health Organization, 1993.

18 Cattaneo A, Davanzo R, Ronfani L. Are data on the prevalence and duration of breastfeeding reliable? The case of Italy. Acta Paediatrica 2000; 89(1): 88-93.

19 Nicoll ATB, Newell ML, Rundall P. Breastfeeding policy, promotion and practice in Europe. Results of a survey with non-governmental organizations. Journal of Nutrition and Environmental Medicine 2002; 12: 255-64.

20 ESPGAN. Committee on Nutrition: Guidelines on infant nutrition. III. Recommendations for infant feeding. Acta Paediatrica 1982; (Suppl. 302): 1-27.
21 American Academy of Pediatricians. Work Group on Breastfeeding: Breastfeeding and the use of human milk. Pedatrics 1997; 100: 1035-9.

22 Neonatologia SId. Raccomandazioni sull'alattamento materno per i nati a termine, di peso appropriato, sani. Medico e Bambino 2002; 21: 91-8.

23 Agence Nationale d'Accreditation et d'Évaluation en Santé (ANAES). Allaitement maternel: mise en oeuvre et poursuite dans les six premiers mois de vie de l'enfant. Paris: ANAES, 2002.

24 Kramer MS, Chalmers B, Hodnett ED, Sevkovskaya Z, Dzikovich I, Shapiro S, et al. Promotion of Breastfeeding Intervention Trial (PROBIT): a randomized trial in the Republic of Belarus. Journal of the American Medical Association 2001; 285(4): 413-20.

25 Cattaneo A, Buzzetti R. Effect on rates of breast feeding of training for the baby friendly hospital initiative. British Medical Journal 2001; 323(7325): 1358-62.

26 Fairbank L, O'Meara S, Renfrew MJ, Woolridge M, Sowden AJ, Lister-Sharp D. A systematic review to evaluate the effectiveness of interventions to promote the initiation of breastfeeding. Health Technology Assessment 2000; 4(25): $1-171$.

27 McInnes RJ, Love JG, Stone DH. Evaluation of a communitybased intervention to increase breastfeeding prevalence. Journal of Public Health Medicine 2000; 22(2): 138-45.

28 Dennis CL, Hodnett E, Gallop R, Chalmers B. The effect of peer support on breast-feeding duration among primiparous women: a randomized controlled trial. Canadian Medical Association Journal 2002; 166(1): 21-8.

29 Waterston T, Tumwine J. Monitoring the marketing of infant formula feeds. British Medical Journal 2003; 326(7381): $113-4$.

30 Galtry J. The impact on breastfeeding of labour market policy and practice in Ireland, Sweden, and the USA. Social Science \& Medicine 2003; 57(1): 167-77. 